\title{
Association of meal timing with dietary quality in a Serbian population sample
}

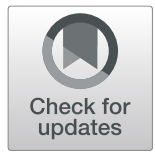

Zora Djuric $^{1^{*}}$ D, Marina Nikolic ${ }^{2,3}$, Milica Zekovic ${ }^{2}$, Melissa Plegue ${ }^{1}$ and Marija Glibetic ${ }^{2}$

\begin{abstract}
Background: The world-wide adoption of Western lifestyles and eating patterns is associated with adverse effects on nutrient intakes. Here we evaluated the relationships between timing of meals and diet quality in Serbia, a Balkan country with a traditional eating pattern that includes the largest meal of the day as a late lunch.

Methods: A dietary survey was done in the Republic of Serbia using a nationally-representative sample of 74 children and 260 non-pregnant adults. Nutrient intakes were calculated from two 24-h recalls. A Dietary Quality Score (DQS) enumerated how many European Union (EU) Science Hub recommendations were met for fruit and vegetables, fiber, saturated fat, sodium, and sugar. We evaluated whether the timing of dietary intakes is associated with DQS and body mass index.
\end{abstract}

Results: The dietary intakes of children ages 10-17 and adults were similar and were high in total fat intake, with an average of $40 \%$ of energy from fat. Mean fruit and vegetable intakes of $473 \mathrm{~g} /$ day in adults exceeded the minimal EU recommendation. The most worrisome aspects of the Serbian diet were high intakes of saturated fat, sugar and sodium. Lunch was the meal with the highest mean content of energy, followed by breakfast and dinner, and the average time for lunch was 15:15. Consumption of a higher percentage of calories before 16:00 in adults was associated with higher fruit and vegetable intakes and with higher DQS. The subgroup of adults consuming their largest meal after 20:00 had a lower mean age, more men, and a larger percentage was employed outside of the home. There were no associations of meal timing with BMI, but the prevalence of obesity in this population sample was only $13 \%$.

Conclusions: These results indicate that an earlier meal pattern, and especially consuming the largest meal of the day earlier in the day, was associated with better quality diets. Public health efforts are needed to preserve nutrient intakes as the population shifts away from the traditional Serbian eating pattern. Long-term, deterioration of nutrient intakes could contribute to the increasing rates of obesity that have been observed in Serbia and world-wide.

Keywords: Nutrition assessment, Serbia, Diet quality, Meal timing, EU recommendations

\section{Background}

One of the earliest reports describing diet in Serbia came from the Seven Countries study done more than 50 years ago. The Seven Countries study evaluated the relationships between diet and coronary heart disease in men. The Serbian diet was found to be between 8 and $10 \%$

\footnotetext{
*Correspondence: zoralong@umich.edu

'Department of Family Medicine, Rogel Cancer Center, University of Michigan, Ann Arbor, Ml 48109-1213, USA

Full list of author information is available at the end of the article
}

saturated fat and yet the rate of cardiovascular diseases was low relative to that in other nearby locations with a similar saturated fat intake [1]. Currently, Serbia is classified as an upper middle income country with a developing economy, and economic development results in changing lifestyles [2]. Rates of obesity, an important risk factor for cardiovascular diseases, diabetes and cancer, are lower in Serbia than in the U.S. and many other upper-income countries, but obesity is increasing in Serbia [3-5]. Cardiovascular diseases and diabetes are 
now pressing public health problems in Serbia [6]. Cancer incidence is also increasing, as it is in most countries worldwide [7].

There is, however, little information available on dietary intakes in Serbia at the present time and what aspects of this diet impact on obesity. A limited number of published studies evaluated diets in children and adolescents in Serbia. These studies collected data six or more years ago and were mainly focused on children, on nutrition knowledge, and on frequency of consuming select foods without capturing the amount of intake $[6,8-10]$. There is also limited dietary information from the Serbian National Health Survey of 2013. This survey collected information on disease prevalence, BMI, physical activity and eating habits in terms of foods eaten on a daily or weekly basis. Some improvements were noted since 2006, with decreasing intakes of animal fats, especially in urban areas, but whole grain bread intake decreased $[6,11]$. This population-level data is valuable but a nation-wide, formal dietary assessment from which nutrient intakes can be calculated is lacking [12]. The recently established database for the nutrient content of Serbian foods will facilitate this assessment [13].

To establish the methodology for a large, nation-wide nutrition survey, we obtained pilot data on a nationallyrepresentative sample of 334 individuals. The sampling methodology was designed to reflect the demographic distribution of the Serbian population as whole. Dietary data was collected using two un-announced 24-h recalls following the guidelines of the European Food Safety Authority and a standard demographic questionnaire $[14,15]$. In this nationally-representative sample, we report the relationships between timing of meal intakes, BMI and major indicators of dietary quality: fruit, vegetables, fiber, saturated fat, sugar and sodium intakes.

The timing of the traditional Serbian eating pattern also afforded the opportunity to evaluate the impact of meal timing on diet quality and BMI. Traditionally, a late lunch is the largest meal of the day in Serbia, and dinner is typically a light meal. This meal pattern would result in consumption of a major portion calories earlier in the day than in Western cultures. It is, however, a meal pattern that is difficult to sustain when work patterns shift away from an early-day schedule. The objective of this study was to evaluate whether meal timing is related to obesity and diet quality in a Serbian population.

\section{Methods}

\section{Subjects}

The study was approved by the Ethics committee of the Institute for Medical Research, University of Belgrade (Dossier No. EO123/2017), and all procedures involving human subjects were in accordance with the Declaration of Helsinki. Written informed consent was obtained from each participant. In the case of children younger than 18 years of age, a parent gave consent and the child gave assent. The interviews were conducted between July and December of 2017.

The study sample was designed to be representative of the Serbian population as determined by the latest census from 2011 [16]. Sampling was stratified by age groups $(10-17,18-64,65-74)$, by gender, and by region of residence. The regions of residence in Serbia were Vojvodina, South East Serbia, West Serbia and Belgrade. Recruitment was organized and conducted by project team members at the household level, with not more than one individual recruited per household. The survey plan was structured to capture a representative proportion of weekdays and weekend days for the study sample. Interviewers were advised to organize home visits to participants whenever possible. If it was not possible, another interview site was agreed upon depending on the region and location of the interviewer's office. For the present analysis, pregnant women $(n=15)$ were excluded, resulting in a total of 334 non-pregnant subjects.

\section{Questionnaire}

Two interviews were done with each subject, at least 1 week apart. The first interview consisted of collecting anthropometric data, administering a demographic questionnaire, and a 24-h dietary recall (see section on dietary assessment below). All of the initial interviews were done in person. Anthropometric data (height, weight) were measured for $65 \%$ of the study population. For the rest, self-reported values were collected. The study questionnaire collected demographic information on age, gender, marital status, place of residence, ethnicity, employment, education, smoking, height, weight, physical activity and health status.

Physical activity was assessed using the International Physical Activity Questionnaire short form that has been published [17]. This included questions on how much time was spent on moderate, vigorous and walking activities in the past 7 days (number of days and hours or minutes each time). For walking, only bouts of at least 10 min were enumerated. Time spent sitting was captured using questions that asked about time spent sitting on weekdays and on weekends. If a participant was not sure of time spent on physical activity, a time of $10 \mathrm{~min} /$ day was input, and this was needed for 23 of the questionnaires. The sitting and physical activity data was used to derive hours per week of activity or of sitting.

\section{Dietary assessment}

The dietary assessment was conducted following the strict guidelines of the European Union (EU) Menu methodology as published previously [15]. In order to estimate usual dietary intakes, two non-consecutive 24-h 
recalls of diet were conducted with an interval of at least a week between the two recalls [14]. A multi-pass method was used to maximize accuracy of the recalls [15]. The multi-pass dietary recall utilized a visual for estimating serving sizes: a pictorial food atlas that was developed for the Balkan region to facilitate precise estimation of portion sizes as published by our group [14]. The first recall was always performed as a face-toface interview and the second recall was conducted faceto-face or via phone, based on participant's availability and preference.

Daily food and nutrient intakes were calculated using the Diet Assess \& Plan software (DELTA Electronic Ltd., Subotica, Serbia). This is an advanced dietary assessment and nutrition planning software tool that has been used previously in national, regional and international nutritional surveys, and it was evaluated in the European Food Safety Authority (EFSA) ring trial involving six countries [18-20]. Nutrient intake calculations were performed using the Serbian Food Composition Database [13]. As published previously, the database was harmonized with European Food Information Resource Network of Excellence (EuroFIR) standards and embedded in the EuroFIR platform and represents the core element of the Balkan Food Platform [13]. Average daily intakes for each subject were derived as a mean of the two 24-h recalls.

\section{Meal timing}

The time of each eating occasion reported during the 24-h dietary recall was recorded. The time noted represents the start of the eating occasion. This varied across the 2 days of intake, and the times for each eating occasion for each subject across the 2 days of intake were averaged. The eating occasions were denoted in the data output as before breakfast, breakfast, morning snack, lunch, afternoon snack, dinner, and after dinner snack. For some subjects, there were two afternoon snacks, resulting in a maximum of eight eating occasions that were recorded for each subject. This data was used to calculate average calories consumed by each subject before 16:00.

\section{Age categories}

Five age categories were created to evaluate differences in diet and BMI by age. The first category was for children ages 10-17. Adults ages 18-64 were categorized into tertiles. Since some people were of the same age, the tertiles are not precisely equal in number. The last category was for adults ages $65-74$ years since the retirement age in Serbia is 65 years.

\section{Diet Quality Score (DQS)}

We computed a DQS for adults to evaluate how many dietary recommendations were being met by each adult subject. This analysis focused on adults only since the number of children in the sample was smaller, dietary recommendations in children differ from that in adults, and health issues are different in children than in adults. The DQS summed the number of dietary recommendations met by each subject.

The dietary recommendations vary from country to country and change over time. We focused on those dietary factors for which healthy eating recommendations have been established as summarized by the European Union (EU) Science Hub of the European Commission [21]. The DQS therefore included one point for meeting each of the EU Science Hub recommendations for fruits and vegetables, fiber, saturated fat, sugar, and sodium as detailed below, resulting in a score of $0-5$.

For fruit and vegetable intakes, recommendations have ranged from 5 servings a day to more than 13 per day, given in $1 / 2$ cup servings [21, 22]. The World Health Organization in 2006 recommended a daily intake of fruit and vegetables of at least $400 \mathrm{~g} /$ day [23]. Using an estimate of $85 \mathrm{~g}$ vegetables or fruit in a $1 / 2$ cup serving, $400 \mathrm{~g} /$ day is about 5 servings/day. Intakes of $400 \mathrm{~g} /$ day or higher therefore received one point. Fiber recommendations are typically $25-35 \mathrm{~g} /$ day, often provided in a sex-specific and agespecific manner. An adequate intake for both children and adults is $14 \mathrm{~g} / 1000 \mathrm{kcal}$ in the Dietary Guidelines for Americans, which harmonizes well with the European recommendations [21]. We therefore awarded one point for meeting or exceeding an intake of $14 \mathrm{~g}$ fiber $/ 1000 \mathrm{kcal}$.

Recommendation for sugar intake generally include consuming less than $10 \%$ of energy from added sugars, and we used that recommendation for awarding a point in the DQS [21]. For fat intake, moderate intakes of total fat $(20-35 \%$ of energy) have been recommended in the past, but more recent evidence shows little associations of total fat intake with disease risks [21]. The recommendations have been more consistent for limiting saturated fat, and we therefore used less than $10 \%$ of calories from saturated fat as the cut-off to award a point in the DQS. For sodium intake, recommendations are to limit intake to $2.0-2.4 \mathrm{~g} /$ day, and we awarded a point towards the DQS for sodium intakes less than $2.3 \mathrm{~g} /$ day [21].

Whole grain intake was not available from our data set and was not used as a criterion, but this likely does overlap with fiber intake which we did include. Protein and water intakes also were not used in the score. An average requirement of $0.60-0.66 \mathrm{~g}$ protein $/ \mathrm{kg}$ body weight has been set as a recommendation across countries [21]. In our population sample, only 14 subjects (5 children and 9 adults) reported consuming less than $0.6 \mathrm{~g} / \mathrm{kg}$ protein, and the mean was $1.1 \mathrm{~g}$ protein $/ \mathrm{kg}$ for adults. Protein intake therefore was not used as criterion in the DQS. Recommendations for water intakes have not been widely made and the recommendations vary from 1000 to $2700 \mathrm{ml} /$ day [21]. This made it difficult to select a 
scoring criterion for water intake and it was omitted from the DQS.

To generate a continuous DQS, we constructed a Diet Quality z-Score. Normalized intakes for each nutrient or food were calculated as the difference between each subjects' value and the recommended value divided by the standard deviation. The differences were taken using positive values for dietary intakes that exceed the recommendations for fiber $(14 \mathrm{~g} / 1000 \mathrm{kcal})$ and fruit/vegetable intakes $(400 \mathrm{~g} /$ day), and negative values for dietary intakes that exceeded the recommended limit for saturated fat ( $10 \%$ of energy), sodium $(2300 \mathrm{mg} /$ day $)$ and sugar (10\% of energy). The Diet Quality z-Score was calculated by summing the five normalized nutrient or food scores.

\section{Statistical analyses}

Data from the demographic questionnaire and from the nutrition analysis program was maintained in Excel. All statistical analyses were conducted in IBM SPSS Statistics for Windows, Version 24.0. (IBM Corp., Armonk, NY). Comparisons between groups (adults versus children, or early versus late eaters), were made using twosample, two-sided $t$-tests for continuous variables or by using Pearson Chi-square tests for categorical variables. Correction of $p$-values for false discovery rates (FDR) was done using the method of Benjamini and Hochberg [24]. Trends of DQS versus percent of calories consumed before 16:00 were explored using linear regression models, adjusting for participant age and gender. Comparisons of energy intakes in three ordinal categories of DQS, defined by DQS scores of $0-1,2-3$, or 4-5, were evaluated using ANOVA, and natural log transformation of the data to achieve normality was used for the $\mathrm{kcal} /$ day variable. The Tukey honest significance test was used post-hoc to control for multiple comparisons.

To evaluate the effects of age category and gender on dietary intakes, linear regression models for each of the key dietary intake outcomes were constructed (fruit and vegetables, fiber, saturated fat, sodium and sugar). These models included age category, gender and the interaction between age and gender as predictors. When the interaction was not significant it was removed to assess the main effects of age category and gender.

Calorie content across the three main meals, breakfast, lunch and dinner (Fig. 1), was compared using linear mixed models with kilocalories per meal as the outcome. The model included meal as a categorical covariate and a random intercept was used to account for within person correlation. Separate models for children and adults were constructed, and an overall model with an interaction between age group and meal was also investigated. We also calculated the timing of the largest meal of the day, averaged across 2 days of assessment for each subject, based upon energy content of the reported meals. Histograms were constructed to evaluate the timing of when the largest meal was consumed by adults who and do not work outside the home. Reasons for not working outside the home included being retired, currently unemployed, disabled or working as a homemaker.

\section{Results \\ Subject characteristics}

There were 349 study participants who had complete data for both diet and demographics. For the present analysis of diet quality, we removed 15 pregnant subjects. This resulted in a data set of 74 children and 260 adults. The vast majority of respondents self-identified as being Serbian (90\%); 10 subjects were Montenegrian, 3 Croatian, 1 Hungarian, and 8 specified their ethnicity as "other". The surveys were carried out in the calendar year 2017, and most were completed in the fall (85\%), with an additional $11 \%$ in the summer.

Of the 334 subjects, 74 reported having a chronic health condition at the present time: 35 with cardiovascular diseases or hypertension, 9 respiratory conditions, 5 diabetes, 3 pre-diabetes, 4 hypothyroidism, 3 mental health issues, and 15 other health issues. Ten of these individuals reported consuming a diet that was altered in some way due to their health condition (mean age 51 years, 5 females). Eight other individuals reported following a weight loss diet and 16 individuals reported following a vegetarian diet. Twenty-seven adult subjects (10\% of all adults) reported consuming more than 2 drinks/day, on average.

As shown in Table 1, 90\% of the study participants lived in areas classified as urban cities. Urban/rural residence did not differ by participant age category $(p=$ 0.55). Education was classified according to International Standard Classification of Education 97 system. The proportion of study participants with some type of education beyond a high school diploma (either at least some college or a technical school) did not differ significantly by adult age category but it was lowest for adults in the oldest age category. The prevalence of overweight or obesity was higher in the oldest adult age category, as shown in Table 1.

\section{Overweight and obesity}

Body weight and height was measured by study interviewers for $65 \%$ of the study sample, and the remainder of this data was from self-report. Body weight and height was missing for 6 subjects. Body mass index (BMI) was calculated as $\mathrm{kg} / \mathrm{m}^{2}$. Of 254 adults with complete weight and height data, 34 were obese with BMI $\geq 30 \mathrm{~kg} / \mathrm{m}^{2}$ $(13 \%)$ and 84 were overweight (BMI $\geq 25 \mathrm{~kg} / \mathrm{m}^{2}$ and $<$ $30 \mathrm{~kg} / \mathrm{m}^{2}, 33 \%$ ). In adults, Spearman correlations of BMI with DQS, percent of calories consumed before $4 \mathrm{pm}$, the number of eating occasions/day, minutes/day spent 


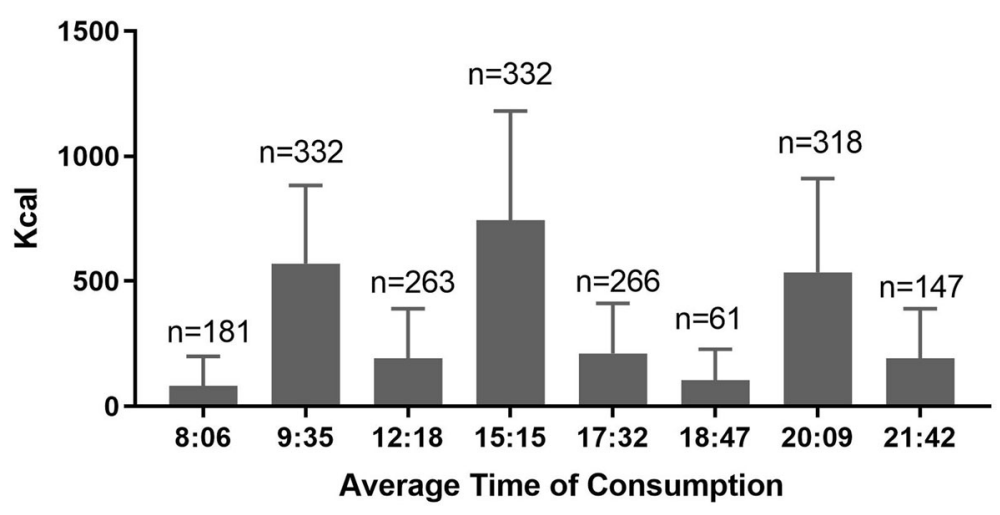

Fig. 1 Mean energy intakes (with SD) across eating occasions in 334 adults and children. Breakfast was at about 9 am, lunch at 3 pm and dinner at $8 \mathrm{pm}$. The other eating occasions were reported as snacks. For both children and adults, linear mixed models indicated that lunch had a significantly higher calorie content than either breakfast or dinner, and there were no significant differences in calorie content between breakfast and dinner

sitting, and with minutes/week spent on moderate and vigorous activity were not statistically significant. Adult BMI was positively correlated with age, Spearman $\rho=0.401$, $p<0.001$. These results were similar when restricted to data using only the 151 subjects with measured BMI values: $11 \%$ were obese, $33 \%$ were overweight, and BMI was correlated with age (Spearman $\rho=0.358, p<0.001$ ) but not with physical activity or time spent sitting.

\section{Dietary intakes}

Table 2 shows mean dietary intakes in the Serbian population sample to facilitate comparison to dietary recommendations compiled by the European Commission [21]. Mean fruit and vegetable intakes were above the minimal recommendation of $400 \mathrm{~g} / \mathrm{day}$, and the range of intakes reported was $15-1783 \mathrm{~g} /$ day (Table 2). All study participants had at least some intake of fruits and vegetables, all the children and all except two adults had some vegetable intake, and $23 \%$ of children and $20 \%$ of adults had no fruit intake. Mean water intake of 2191 $\mathrm{ml} /$ day also was within the recommendations, although the recommendation made span a wide range of 1000 $2700 \mathrm{ml} /$ day for persons over the age of 14 [21]. Total fluid intakes from water and all other beverages other than liquor were higher: $2653 \mathrm{ml} /$ day for children and $3027 \mathrm{ml} /$ day for adults. Fiber was derived mainly from three groups of foods: fruits and vegetables (38\%), grains (33\%), and seeds and nuts (12\%). Mean fiber intake reached the recommendation for consuming at least 14 $\mathrm{g} / 1000 \mathrm{kcal}$ only in adults of ages $65-74$..

The mean intake of total fat at $40 \%$ of energy was higher than what is considered to be a moderate range, generally defined as $20-35 \%$ of energy from total fat [21]. Saturated fat intake was a mean of $13 \%$ of energy in this study population (below $10 \%$ of energy is recommended), and sugar intake was a mean of $13 \%$ of energy (below 10\% of energy is recommended). Sodium intake was very high with a mean of $3.9 \mathrm{~g} /$ day (less than $2.3 \mathrm{~g} /$ day is generally recommended).

\section{Diet Quality Score (DQS)}

The DQS was a simple sum of the number of EU dietary recommendations that were met for five items: fruits and vegetables, fiber, saturated fat, sugar, and sodium. One point was awarded for meeting the recommendation in each of the five categories. Whole grain intake in servings was not available in this diet analysis, but 33\% of dietary fiber in this study sample was obtained from total grain intake. Only 12 adults and one child had a score of 5 , and $78 \%$ of adult subjects had scores of 3 or lower.

Among the individual components of the DQS, fruit and vegetables intakes and fiber were met by about half the subjects, but the numbers meeting the sugar, sodium and saturated fat recommendations were much lower. Among the 260 adult subjects, there were 139 with at least $400 \mathrm{~g} /$ day fruits and vegetables, 130 with at least $14 \mathrm{~g}$ fiber $/ 1000 \mathrm{kcal}, 90$ with less than $10 \%$ of energy from sugar, 66 with $2.3 \mathrm{~g}$ or less of sodium/day, and 58 with a diet $<10 \%$ of energy from saturated fat.

A Diet Quality z-Score was also calculated as a continuous variable using the difference in intake versus the recommendation divided by the standard deviation for each of the five factors as described in Methods. This z-like score takes into account that some intakes might be closer to the recommended levels than others without necessarily meeting the recommendation. Women had significantly higher average DQS z-scores than men (2.7 vs. $2.0, p<0.001$, z-score -1.5 v. $-2.5, p<$ 0.001 ), and z-scores increased with age (Spearman $\rho=$ $0.284, p<0.001)$. 
Table 1 Characteristics of subjects in each age category. Data shown are the mean and SD or the percentage of subjects within each age category with the indicated characteristic

\begin{tabular}{|c|c|c|c|c|c|c|c|c|c|}
\hline $\begin{array}{l}\text { Age } \\
\text { category }\end{array}$ & $\begin{array}{l}\text { Number } \\
\text { a }\end{array}$ & $\begin{array}{l}\text { Age, years (mean } \\
\text { and SD) }\end{array}$ & $\begin{array}{l}\text { Serbian } \\
\text { ethnicity b } \\
(n, \%)\end{array}$ & $\begin{array}{l}\text { Female } \\
(\mathrm{n}, \%)\end{array}$ & $\begin{array}{l}\text { Current } \\
\text { Smoker } \\
(n, \%)\end{array}$ & $\begin{array}{l}\text { Overweight or } \\
\text { Obese }{ }^{b} \\
(n, \%)\end{array}$ & $\begin{array}{l}\text { Post-secondary } \\
\text { education }{ }^{c} \\
(n, \%)\end{array}$ & $\begin{array}{l}\text { Employed } \\
(n, \%)\end{array}$ & $\begin{array}{l}\text { Student } \\
(\mathrm{n}, \%)\end{array}$ \\
\hline $10-17$ & 74 & $14(2)$ & $66(92 \%)$ & $\begin{array}{l}37 \\
(50 \%)\end{array}$ & $4(6 \%)$ & $5(7 \%)$ & 0 & 0 & $\begin{array}{l}67 \\
(92 \%)\end{array}$ \\
\hline $18-29$ & 75 & $25(3)$ & 72 (97\%) & $\begin{array}{l}40 \\
(53 \%)\end{array}$ & $26(35 \%)$ & $20(27 \%)$ & 43 (59\%) & 38 (51\%) & $\begin{array}{l}26 \\
(35 \%)\end{array}$ \\
\hline $30-47$ & 73 & $38(6)$ & 64 (89\%) & $\begin{array}{l}40 \\
(55 \%)\end{array}$ & $24(35 \%)$ & $29(41 \%)$ & $50(70 \%)$ & $62(87 \%)$ & $2(3 \%)$ \\
\hline $48-64$ & 73 & $55(4)$ & 67 (93\%) & $\begin{array}{l}43 \\
(59 \%)\end{array}$ & $25(35 \%)$ & 43 (59\%) & 44 (61\%) & $50(69 \%)$ & 0 \\
\hline $65-74$ & 39 & $69(3)$ & 32 (82\%) & $\begin{array}{l}19 \\
(49 \%)\end{array}$ & 7 (19\%) & $26(70 \%)$ & $18(46 \%)$ & $3(8 \%)$ & 0 \\
\hline All & 334 & 37 (19) & 301 (92\%) & $\begin{array}{l}179 \\
(54 \%)\end{array}$ & $86(27 \%)$ & $123(38 \%)$ & $155(48 \%)$ & $153(46 \%)$ & $\begin{array}{l}95 \\
(29 \%)\end{array}$ \\
\hline
\end{tabular}

${ }^{a}$ A small portion of subjects had missing data for one or more factors: $n=14$ for smoking status, $n=7$ for body mass index, $n=12$ for education, $n=4$ for employment status and $n=5$ for ethnicity. The percentages shown in each column are for subjects who had valid data for that category

b The proportion of subjects differed across the four adult age categories for the indicated variables, as determined by Pearson Chi square tests. These tests evaluated differences in ethnicity, smoking, and overweight/obesity by adult age category, and both ethnicity and overweight/obesity prevalence differed by adult age category ( $p=0.04$ for ethnicity and $p<0.001$ for overweight/obesity)

c Post-secondary education includes individuals who completed at least some college or technical training beyond high school (International Standard

Classification of Education 4). In the total population above age 18, only $8 \%$ did not finish high school (International Standard Classification of Education 0,1 or 2 )

\section{Timing of meals}

The average time for all eating occasions recorded in children and adults is shown in Fig. 1, along with the number of subjects who reported consuming each meal or snack. The average calorie content of meals and snacks is shown for those study participants who reported consuming food on each occasion. All children and almost all of the adults reported eating breakfast, lunch and dinner. There was an average of six eating occasions per day for both adults and children (Table 2). The average calorie content of snacks was smaller than that of the daily meals, and a smaller number of study

Table 2 Nutrient intakes in the Serbian population sample. Data shown is mean (SD)

\begin{tabular}{llll}
\hline Nutrient & $\begin{array}{l}\text { Children } \\
\text { (ages 10-17) } \\
n=74\end{array}$ & $\begin{array}{l}\text { Adults } \\
\text { (ages 18-74) } \\
n=260\end{array}$ & All subjects, $n=334$ \\
\hline Energy (kcal/day) & $2280(951)$ & $2265(987)$ & $2268(978)$ \\
Carbohydrate (\% of energy) & $46(8)$ & $44(10)$ & $44(10)$ \\
Protein (\% of energy) & $15(4)$ & $16(4)$ & $15(4)$ \\
Fat (\% of energy) & $39(8)$ & $40(9)$ & $40(9)$ \\
Saturated Fat (\% of energy) & $12(4)$ & $13(4)$ & $13(4)$ \\
Fiber (g/1000 kcal) & $8.1(3.4)$ & $10.9(6.4)^{a}$ & $10.3(6.0)$ \\
Fruit (g/day) & $169(173)$ & $184(188)^{a}$ & $181(184)$ \\
Vegetables (g/day) & $256(200)$ & $289(207)$ & $281(205)$ \\
Fruit and Vegetables (g/day) & $424(259)$ & $473(295)^{2}$ & $463(288)$ \\
Sodium (g/day) & $3.66(2.69)$ & $3.99(3.00)$ & $3.92(2.93)$ \\
Sugar (\% of energy) & $13.6(6.4)$ & $13.2(7.4)$ & $13.3(7.2)$ \\
Water (ml/day) & $1996(1327)$ & $2246(1333)$ & $2191(1334)$ \\
Protein, g/kg body weight & $1.45(0.56)$ & $1.11(0.46)^{a}$ & $1.19(0.51)$ \\
Energy density (kcal/g food) & $1.01(0.34)$ & $0.89(0.32)^{a}$ & $0.92(0.32)$ \\
\% of energy consumed before 16:00 & $59(16)$ & $61(18)$ & $60(18)$ \\
Number of eating occasions per day & $6.1(1.0)$ & $6.1(1.1)$ & $6.1(1.1)$ \\
\hline
\end{tabular}

${ }^{a}$ Marked variables differed significantly between children and adults by two-sample t-tests, with $p<0.001$ for both fiber and protein, and $p=0.006$ for energy density, each of which remained significant after adjustment for false discovery rates 
participants reported eating snacks than meals, as shown in Fig. 1.

For both children and adults, lunch had a significantly higher mean calorie content than both breakfast and dinner. In children, the marginal mean of $665 \mathrm{kcal}$ (SE 38) for lunch differed from both the $560 \mathrm{kcal}$ (SE 38) for breakfast with $p=0.025$ and the $520 \mathrm{kcal}$ (SE 38) for dinner with $p=0.002$. In adults, the marginal mean of 761 (SE 24) kcal for lunch differed from the $537 \mathrm{kcal}$ (SE 24) for breakfast with $p<0.001$, and from the 568 (SE 24) kcal for dinner with $p<0.001$. The average calorie content between breakfast and dinner was not significantly different in either group ( $p=0.41$ for children and $p=0.29$ for adults). For comparing the calorie content of the three meals using data for children and adults combined, linear mixed models showed that adult status did not have a significant interaction with meal calorie content $(p=0.28)$. The average time lunch was consumed across all subjects was 15:15. Lunch was the largest meal of the day for $47 \%$ of adults. In evaluating individual data for adults, $84 \%$ consumed lunch within $1 \mathrm{~h}$ of the day on the two different days that recalls were done, and on average the difference in timing between the 2 days was $24 \mathrm{~min}$ (SD $54 \mathrm{~min}$ ).

We next evaluated whether the timing of energy intakes was associated with BMI, age, gender and measures of dietary quality (Table 3 ). For adults, the mean percentage of calories consumed by $16: 00$ was $60 \%$. Using two-sample t-tests, adults who consumed at least $60 \%$ of their daily energy intake by 16:00 (4 pm), versus those that did not, were older (mean age 47 vs. 40 years), and consumed greater amounts of fruits and vegetables (mean $521 \mathrm{v} .425$ g/day). Early eaters also consumed less total calories per day (2135 v. $2402 \mathrm{kcal} /$ day), but this was not significant after adjusting for multiple comparisons, and mean DQS was higher although not significantly so (Table 3). Fruit and vegetable intakes were the main statistically significant difference in diet quality between early and late eaters. Other components of the DQS did not differ significantly between the two groups (Table 3).

The standardized Diet Quality z-Score was weakly associated with the percentage of calories consumed by 16 : 00 , with $\beta=0.03$ (SE 0.007), $p<0.001$. Every $10 \%$ increase in calories consumed by 16:00, the Diet Quality zScore increased by a modest 0.3 in an unadjusted regression model. When age and gender were also included in the model, the results were similar $\beta=0.02$ (SE 0.007), $p=0.004$. Age and gender were also related to the Diet Quality z-Score with increased age associated with higher scores and men having lower scores. Mean Diet Quality z-Scores were -2.52 and -1.55 for men and women, respectively.

\section{Timing of the largest meal of the day}

Since there was a fair amount of variability in energy intakes across meals and breakfast was a sizable meal (Fig. 1 ), we sought to identify the timing of the largest meal of the day in more detail. The largest meal was defined as the meal with the highest caloric content. The histograms showing time of consumption of the largest meal among 260 adults stratified by DQS are in Fig. 2. The group with DQS of 4-5 displayed a lower frequency of consuming the largest meal after 20:00 and a higher frequency of consuming at least $60 \%$ of energy before 16:00. Of 50 individuals with DQS of $4-5,72 \%$ consumed $60 \%$ or more of their daily energy before $16: 00$, and this occurred less frequently for adults with DQS of $0-1$ (35 of $75,47 \%$ ) or DQS of 2-3 (58 of 135, 43\%), as shown in (Fig. 2).

The mean percent of energy consumed before 16:00 in adults with DQS of $0-1$ (category 1), DQS of 2-3 (category 2), and DQS of 4-5 (category 3), were $56.6 \%$ (SD 16.5), 60.1\% (SD 18.8) and 68.1\% (SD 16.1), respectively. ANOVA analyses with the Tukey post-hoc tests indicated that the percent of energy consumed before 16:00 was higher in DQS category 3 than in DQS category 2 or 1 with $p<0.02$ in either case. Mean energy intakes were 2528 (SD 1031, $n=75$ ), 2337 (SD 998, $n=135$ ) and 1677 (SD 587, $n=50) \mathrm{kcal} /$ day in the DQS categories of 1,2 and 3, respectively. After natural log transformation to normalize the data, ANOVA analyses with the Tukey post-hoc tests indicated that mean energy intake per day in DQS category 3 was significantly lower than in the two other categories with $p<0.001$ in either case.

Working outside the home did yield a later distribution of when the largest meal of the day was consumed, as shown in Table 4. However, the average hour for consuming the largest meal was similar (15:15 versus 14:56 for working and non-working adults, respectively, $p=$ 0.524 ). The frequency of consuming at least $60 \%$ of energy before 16:00 also was similar in working and nonworking adults (Table 3 ).

\section{Discussion}

In this population-based sample of individuals residing in Serbia, we assessed the impact of meal timing on obesity and diet quality. On average, the EU recommendation for fruits and vegetables was exceeded, and the average intake in $\mathrm{g} /$ day was above the mean of almost $300 \mathrm{~g} /$ day that was reported for fruits and vegetables globally in a review of diet survey from 113 countries during 2010 [25]. At the individual level, however, about half of the study population met the fruit and vegetable recommendations. This was also true for fiber intake (Results). Mean intakes of total and saturated fat, sugar and sodium, however, were all above the desired ranges with only $22-34 \%$ of the sample meeting the recommendation for each of these nutrients [21]. Despite this, the 
Table 3 Characteristics of adult subjects who did or did not consume at least 60\% of their daily energy intake by 16:00

\begin{tabular}{|c|c|c|c|}
\hline Characteristic & $\begin{array}{l}\text { Early eaters } \\
N=133\end{array}$ & $\begin{array}{l}\text { Late eaters } \\
N=127\end{array}$ & $P$-value \\
\hline Percent of calories consumed by $16: 00$ & $75(9)$ & $46(12)$ & $<0.001^{a}$ \\
\hline Total calorie intake, $\mathrm{kcal} / \mathrm{d}$ & $2135(880)$ & $2402(1076)$ & 0.029 \\
\hline Age, years & $47.1(16.6)$ & $39.6(15.2)$ & $<0.001^{\mathrm{a}}$ \\
\hline Female, number and \% & $72(51 \%)$ & $70(48 \%)$ & 0.874 \\
\hline Employed outside the home, number and \% & $78(59 \%)$ & 75 (59\%) & 0.764 \\
\hline BMl, $\mathrm{kg} / \mathrm{m}^{2}$ (all data) & $25.7(3.7)$ & $24.8(4.4)$ & 0.111 \\
\hline BMI, $\mathrm{kg} / \mathrm{m}^{2}$ (measured only, $n=83$ early, $n=68$ late eaters) & $25.6(3.6)$ & $24.5(4.2)$ & 0.103 \\
\hline Overweight or obese, number and \% & $51(38 \%)$ & $67(53 \%)$ & 0.153 \\
\hline Number of eating occasions/day & $6.1(1.1)$ & $6.2(1.0)$ & 0.733 \\
\hline Energy density (kcal/gram food) & $0.87(0.28)$ & $0.92(0.35)$ & 0.219 \\
\hline Fruits and vegetables, g/day & $521(332)$ & $425(242)$ & $0.008^{a}$ \\
\hline Fiber, g/1000 kcal & $11.7(7.1)$ & $10.2(5.5)$ & 0.065 \\
\hline Saturated fat, \% of energy & $13.3(4.7)$ & $13.3(4.3)$ & 0.893 \\
\hline Sugar, \% of energy & $13.4(8.3)$ & $13.1(6.2)$ & 0.748 \\
\hline Sodium, g/day & $4.1(3.6)$ & $3.9(2.3)$ & 0.636 \\
\hline Diet Quality Score of $4-5$, number and $\%^{b}$ & $40(30 \%)$ & $26(21 \%)$ & 0.075 \\
\hline Diet Quality Z-score ${ }^{c}$ & $-1.76(2.48)$ & $-2.23(1.87)$ & 0.089 \\
\hline
\end{tabular}

${ }^{\mathrm{a}}$ The $p$-values shown are from two-sample t-tests or from the Chi-square test for gender and number of people with a Diet Quality Score of 4 or 5 . After adjustment for false discovery rates, $p<0.01$ remained statistically significant

${ }^{\mathrm{b}}$ The Diet Quality Score (DQS) enumerates how many EU dietary recommendations were met on a scale of 0 to 5 . The five dietary recommendations included in the score were fruit and vegetable servings, saturated fat, sodium, sugar and fiber

c Each component of the DQS was z-transformed and summed to create a continuous variable

prevalence of overweight and obesity combined was only $45 \%$ for this sample of Serbian adults. Serbia as whole does have lower rates of overweight and obesity than Western countries such as the U.S. where $72 \%$ of the population is overweight or obese [5]. The prevalence of obesity in this Serbian population sample surveyed in 2017 was only $13 \%$ which is dramatically less than that in the U.S. where $40 \%$ of the population was obese in 2015-2016 [5, 26]. Unfortunately, obesity rates are increasing in Serbia as they are world-wide [3-5].

One interesting characteristic of the traditional Serbian diet is that lunch is the largest meal of the day. Lunch was consumed, on average, in the middle of the afternoon at 15:15 (Fig. 1). In Serbia, the traditional lunch is a large, cooked meal with soup followed by meat and vegetables. Other meals are rarely cooked and instead typically consist of bread, cheese, processed meats, salad, or ready-made foods purchased from a bakery such as the traditional filo and cheese dish, gibanica [27]. How this eating pattern may be changing as the economy develops and Western living patterns are adopted is not yet defined. Meal timing is also a part of the so-called "nutrition transition" away from culturally-traditional eating patterns [28]. Globally, the timing of meals across countries does vary, and it also appears that early eating could be helpful for weight control [29,
30]. In this sample of Serbian adults, meal timing was associated with diet quality but not with obesity. An association with obesity may emerge, however, if the trends away from the traditional eating pattern with declining diet quality become more prevalent and persist over time.

Many studies have shown that eating later in the day is associated with obesity and adult weight gain [31-33], although not all studies agree [34]. Consuming more calories earlier in the day also could allow for a longer fast overnight, and extending the overnight fast is reported to improve metabolic health $[35,36]$. In addition, consuming breakfast daily has emerged as a strategy to avoid weight gain [36-38]. Results of the present study are consistent with these findings since eating a larger percentage of calories by 16:00 and completing food consumption before 20:00 was associated with better diet quality.

In agreement with our data, the Serbian National Health Survey of 2013 showed that the proportion of females consuming fruits and vegetables on a daily basis was higher versus that in males [11]. The reported intakes of fruits and vegetables overall were lower than the average for Europe, and more than half of the Serbian population was found to either not eat fruit or eat fruit rarely based on a diet questionnaire [11]. In our study that was completed in 2017, only one-fifth of the sample 


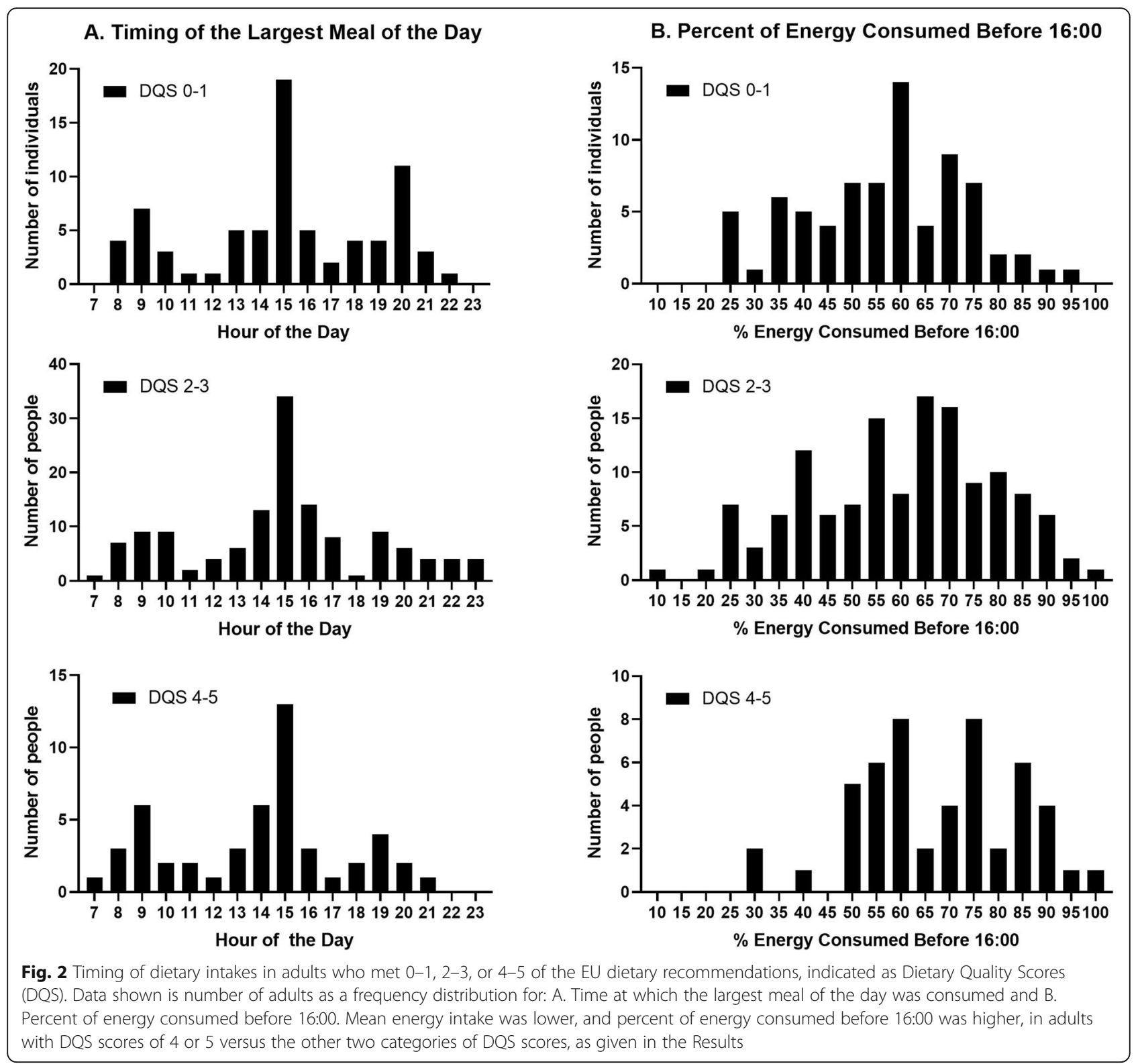

had no fruit intake and every individual consumed at least some fruits and vegetables across the 2 days of assessment. Mean intake of fruits and vegetables was above the EU recommendation. With the recall method we used and formal analysis of all foods eaten, small amounts of fruits and vegetables in mixed dishes are enumerated and this might not be readily quantified using a questionnaire.

Limitations of the present study are that diet and health behaviors were self-reported. There is evidence that persons who have overweight or obesity underreport dietary intakes $[39,40]$. We maximized accuracy by using a multi-pass method for the dietary recalls and by following strict EFSA guidelines for nutrition assessment, but this limitation should be recognized. Most of the surveys were carried out in the fall, and dietary intakes do vary somewhat by season, with lowest calorie intakes reported in the winter [41]. In addition, some of the BMI data was by self-report, but mean BMI and the associations that we evaluated with BMI were similar with and without the self-reported data. In a review of studies that addressed the accuracy of self-reported weight and height, self-reported BMI was found to range 0-2.2 BMI units lower than measured BMI [42]. Strengths of the study include that the population sample was designed to reflect the Serbian population as a whole, the data add to the very limited information available about Serbian diets, and that the timing of all eating occasions was captured such that the effect of meal timing on diet quality could be evaluated. 
Table 4 Characteristic of Adults Who Do or Do Not Report Eating After 20:00. Data shown is mean and SD or number and percent for 260 non-pregnant, adults

\begin{tabular}{|c|c|c|c|}
\hline Characteristic & Consume Food After 20:00, $n=193$ & Do Not Eat After 20:00, $n=67$ & $P$-value ${ }^{a}$ \\
\hline Age, years & $41.6(15.6)$ & $48.8(17.3)$ & $0.002^{\mathrm{a}}$ \\
\hline Female, number and \% & $98(51 \%)$ & $44(66 \%)$ & $0.035^{\mathrm{a}}$ \\
\hline Smoker, number and \% & $117(63 \%)$ & $52(81 \%)$ & $0.006^{\mathrm{a}}$ \\
\hline Employed outside the home, number and \% & $121(63 \%)$ & $32(49 \%)$ & $0.034^{\mathrm{a}}$ \\
\hline BMl, $\mathrm{kg} / \mathrm{m}^{2}$ (measured only, $n=114$ and $n=37$, respectively) & $25.1(4.0)$ & $25.0(3.8)$ & 0.832 \\
\hline $\mathrm{BMl}, \mathrm{kg} / \mathrm{m}^{2}$ & 25. $1(4.0)$ & $25.7(4.3)$ & 0.334 \\
\hline Overweight or obese, number and \% & $84(44 \%)$ & $34(51 \%)$ & 0.273 \\
\hline Percent of Energy consumed before 16:00 & $57(18)$ & $70(15)$ & $<0.001^{\mathrm{a}}$ \\
\hline Total calorie intake, kcal/d & $2407(1011)$ & $1857(787)$ & $<0.001^{\mathrm{a}}$ \\
\hline Energy density (kcal/g food) & $0.91(0.33)$ & $0.84(0.28)$ & 0.108 \\
\hline Number of eating occasions/day & $6.1(1.1)$ & $6.2(1.1)$ & 0.896 \\
\hline Fruits and vegetables, g/day & $464(289)$ & $501(311)$ & 0.374 \\
\hline Fiber, g/1000 kcal & $10.4(6.8)$ & $12.4(5.1)$ & $0.030^{\mathrm{a}}$ \\
\hline Saturated fat, $\%$ of energy & $13.8(4.5)$ & $11.9(4.1)$ & $0.002^{\mathrm{a}}$ \\
\hline Sugar, $\%$ of energy & $12.3(6.1)$ & $15.9(9.7)$ & $0.001^{\mathrm{a}}$ \\
\hline Sodium, g/day & $4.2(3.1)$ & $3.2(2.7)$ & $0.020^{a}$ \\
\hline Diet Quality Score $4-5^{b}$, number and \% & $36(19 \%)$ & $30(45 \%)$ & $<0.001^{a}$ \\
\hline$z$-Diet Quality Score ${ }^{c}$ & $-2.2(2.1)$ & $-1.4(2.5)$ & $0.009^{a}$ \\
\hline
\end{tabular}

${ }^{a} P$-values are from the Person Chi-square for categorical variables or from two-sample t-tests for continuous variables. After correction for False Discovery Rates, $p<0.036$ was significant, as marked

${ }^{b}$ The number of individuals with a Diet Quality Score (DQS) 4 or 5 is shown. The range of DQS was $0-5$

${ }^{\mathrm{C}}$ The z-Diet Quality Score was calculated as the sum of z-scores for each of the five diet quality criteria

\section{Conclusions}

The major findings are that the dietary factors of greatest concern in the Serbian diet were saturated fat, sugar and sodium. Half the sample met with EU recommendations for fruits and vegetables and for fiber. An earlier meal pattern, and especially consumption of the largest meal of the day earlier in the day, was associated with better quality diets. A later meal pattern conversely represents a departure from the traditional Serbian eating pattern and was more prevalent in younger individuals, men and working adults. Shifting meal timing to accommodate changes in lifestyles may be a necessity, but efforts are needed to find ways to improve dietary quality while changes in meal consumption take place.

\section{Abbreviations}

BMI: Body mass index; DQS: Diet Quality Score; EFSA: European Food Safety Authority; EU: European Union; EuroFIR: European Food Information

Resource Network of Excellence; SE: Standard error

\section{Acknowledgements}

We thank all the individuals who consented to participate in this survey.

\section{Authors' contributions}

All authors participated in designing the data analysis plan and all authors read and approved the manuscript. Additional roles of authors were: ZD analysed data and wrote the manuscript; $M N$ organized data and edited the manuscript; MZ organized data and edited the manuscript; MP analysed data; and MG conceptualized the overall study, obtained funding to carry it out, and edited the manuscript.

\section{Funding}

Support for collecting and analysing the data at the Center for Excellence in Nutrition and Metabolism Research was obtained by Dr. Maria Glibetic from the Ministry of Education, Science and Technological Development of the Republic of Serbia (grant number III 41030) and the European Food Safety Authority. A Fulbright Global Scholar Award from the U.S. Department of State supported the travel and effort of Dr. Zora Djuric to make this collaboration possible.

\section{Availability of data and materials}

The datasets analyzed during the current study are available from the senior author on request for data presented in aggregate to protect anonymity of subjects.

\section{Ethics approval and consent to participate}

The study was approved by the Ethics committee of the Institute for Medical Research, University of Belgrade (Dossier No. EO123/2017). Subjects gave written, informed consent to participate in the study.

Consent for publication

Not applicable.

\section{Competing interests}

The authors have no competing interests to declare.

\section{Author details}

'Department of Family Medicine, Rogel Cancer Center, University of Michigan, Ann Arbor, MI 48109-1213, USA. ${ }^{2}$ Center for Research Excellence in Nutrition and Metabolism, University of Belgrade, Belgrade 11158, Serbia.

${ }^{3}$ Present Address: European Food Safety Authority, Via Carlo Magno 1A, 43126 Parma, Italy. 
Received: 14 January 2020 Accepted: 27 August 2020

Published online: 22 October 2020

\section{References}

1. Keys A. Coronary heart disease in seven countries. XII. Three cohorts of men followed five years in Serbia. Circulation. 1970;41(Suppl. 4):1123.

2. World Bank Group. Country Data 2019 [Available from: https://data. worldbank.org/country/serbia. Accessed 2 May 2019.

3. Sekulic M, Vasiljevic D, Radevic S, Djonovic N. Socioeconomic inequalities in overweight and obesity in Serbia: data from 2013 National Health Survey. Front Pharmacol. 2017:8:967.

4. World Health Organization. Nutrition, Physical Activity and Obesity: Serbia 2013 [Available from: http://www.euro.who.int/_data/assets/pdf_file/001 7/243323/Serbia-WHO-Country-Profile.pdf?ua=1. Accessed 29 Dec 2019.

5. Hales CM, Carroll MD, Fryar CD, Ogden CL. Prevalence of obesity among adults and youth: United States, 2015-2016. In: NCHS Data Brief No. 288. Hyattsville: National Center for Health Statistics; 2017.

6. Hic M, llic I, Stojanovic G, Zivanovic-Macuzic I. Association of the consumption of common food groups and beverages with mortality from cancer, ischaemic heart disease and diabetes mellitus in Serbia, 1991-2010: an ecological study. BMJ Open. 2016;6(1):e008742.

7. Global Burden of Disease Cancer Collaboration, Fitzmaurice C, Allen C, Barber RM, Barregard L, Bhutta ZA, et al. Global, Regional, and National Cancer Incidence, Mortality, Years of Life Lost, Years Lived With Disability, and Disability-Adjusted Life-years for 32 Cancer Groups, 1990 to 2015: A Systematic Analysis for the Global Burden of Disease Study. JAMA Oncol. 2017:3(4):524-48.

8. Jovicic AD. Healthy eating habits among the population of Serbia: gender and age differences. J Health Popul Nutr. 2015;33(1):76-84.

9. Pavlovic M, Grujic V, Oshaug A. Nutrition and physical activity of the population in Serbia. World Rev Nutr Diet. 2005;94:51-9.

10. Sumonja S, Novakovic B. Determinants of fruit, vegetable, and dairy consumption in a sample of schoolchildren, northern Serbia, 2012. Prev Chronic Dis. 2013;10:E178.

11. Ilić D. Results of the National Health Survey of Serbia, 2013. Belgrade: The Institute of Public Health of Serbia; 2014. Available from: http://www.batut. org.rs/download/publikacije/2013SerbiaHealthSurvey.pdf.

12. Rippin HL, Hutchinson J, CEL E, Jewell J, Breda JJ, Cade JE. National nutrition surveys in Europe: a review on the current status in the 53 countries of the WHO European region. Food Nutr Res. 2018;62. https://doi.org/10.29219/fnr. v62.1362 eCollection 2018

13. Gurinovic M, Milesevic J, Kadvan A, Djekic-Ivankovic M, Debeljak-Martacic J, Takic M, et al. Establishment and advances in the online Serbian food and recipe data base harmonized with EuroFIR standards. Food Chem. 2016;193:30-8.

14. Nikolic M, Milesevic J, Zekovic M, Gurinovic M, Glibetic M. The development and validation of food atlas for portion size estimation in the Balkan region. Front Nutr. 2018;5:78.

15. European Food Safety Authority. Guidance on the EU menu methodology. EFSA J. 2014;12(12):3944

16. Statistical Office of the Republic of Serbia: Census 2011. Available at https:// www.stat.gov.rs/en-us/oblasti/popis/popis-2011. Accessed 28 Dec 2018.

17. International Physical Activity Questionnaire Group. International Physical Activity Questionnaire 2019 [Available from: https://sites.google.com/site/ theipaq/questionnaire_links. Accessed 30 Dec 2018.

18. Gurinovic M, Milesevic J, Kadvan A, Nikolic M, Zekovic M, Djekic-Ivankovic M, et al. Development, features and application of DIET ASSESS \& PLAN (DAP) software in supporting public health nutrition research in Central Eastern European Countries (CEEC). Food Chem. 2018;238:186-94.

19. Gurinovic M, Milesevic J, Novakovic R, Kadvan A, Djekic-Ivankovic M, Satalic Z, et al. Improving nutrition surveillance and public health research in central and Eastern Europe/Balkan countries using the Balkan food platform and dietary tools. Food Chem. 2016;193:173-80.

20. Gavrieli A, Trichopoulou A, Valsta LM, loannidou S, Berry R, Roe M, et al. Identifying sources of measurement error in assessing dietary intakes - results of a multi-country ring-trial. Nutr Metab Cardiovasc Dis. 2019;29(2):127-34.

21. European Commission. EU science hub: health promotion and disease prevention knowledge gateway 2018 [updated 28 November 2017. Available from: https://ec.europa.eu/jrc/en/health-knowledge-gateway/ promotion-prevention/nutrition. Accessed 30 Dec 2018.

22. Lee-Kwan SH, Moore LV, Blanck HM, Harris DM, Galuska D. Disparities in state-specific adult fruit and vegetable consumption - United States, 2015. Morb Mortal Wkly Rep. 2017;66:1241-7.
23. World Health Organization. Comparative analysis of nutrition policies in the WHO European Region. Copenhagen: WHO; 2006. http://www.euro.who. int/_data/assets/pdf_file/0004/149782/instanbul_conf_20ebd02.pdf.

24. Benjamini Y, Hochberg Y. Controlling the false discovery rate: a practical and powerful approach to multiple testing. J Royal Stat Soc B. 1995;57:289-300.

25. Micha R, Khatibzadeh S, Shi P, Andrews KG, Engell RE, Mozaffarian D, et al. Global, regional and national consumption of major food groups in 1990 and 2010: a systematic analysis including 266 country-specific nutrition surveys worldwide. BMJ Open. 2015;5(9):e008705.

26. CDC/National Center for Health Statistics. Obesity and Overweight (FastStats) 2016 Available from: https://www.cdc.gov/nchs/fastats/obesityoverweight.htm.

27. Popović TB, Arsić AČ, Martačić JDD, Oggiano GPP, Gurinović MA, Vučić VM, et al. Traditional food in Serbia: sources, recipes and fatty acids profiles. Food Feed Res. 2014:41(2):153-8.

28. Chee VA, Teran E, Hernandez I, Wright L, Izurieta R, Reina-Ortiz M, et al. 'Desculturizacion,' urbanization, and nutrition transition among urban Kichwas Indigenous communities residing in the Andes highlands of Ecuador. Public Health. 2019;176:21-8.

29. Lopez-Minguez J, Gomez-Abellan P, Garaulet M. Timing of breakfast, lunch, and dinner. effects on obesity and metabolic risk. Nutrients. 2019;11(11):2624

30. Maukonen M, Kanerva N, Partonen T, Mannisto S. Chronotype and energy intake timing in relation to changes in anthropometrics: a 7-year follow-up study in adults. Chronobiol Int. 2019;36(1):27-41.

31. McCrory MA, Shaw AC, Lee JA. Energy and nutrient timing for weight control: does timing of ingestion matter? Endocrinol Metab Clin N Am. 2016;45(3):689-718.

32. McHill AW, Phillips AJ, Czeisler CA, Keating L, Yee K, Barger LK, et al. Later circadian timing of food intake is associated with increased body fat. Am J Clin Nutr. 2017;106(5):1213-9.

33. Nimitphong $H$, Siwasaranond N, Saetung S, Thakkinstian A, Ongphiphadhanakul B, Reutrakul S. The relationship among breakfast time, morningness-eveningness preference and body mass index in type 2 diabetes. Diabet Med. 2018;35(7):964-71.

34. Fong $\mathrm{M}$, Caterson ID, Madigan CD. Are large dinners associated with excess weight, and does eating a smaller dinner achieve greater weight loss? A systematic review and meta-analysis. Br J Nutr. 2017;118(8):616-28.

35. Sutton EF, Beyl R, Early KS, Cefalu WT, Ravussin E, Peterson CM. Early timerestricted feeding improves insulin sensitivity, blood pressure, and oxidative stress even without weight loss in men with Prediabetes. Cell Metab. 2018; 27(6):1212-21 e3.

36. St-Onge MP, Ard J, Baskin ML, Chiuve SE, Johnson HM, Kris-Etherton P, et al. Meal timing and frequency: implications for cardiovascular disease prevention: a scientific statement from the American Heart Association. Circulation. 2017;135(9):e96-e121.

37. Kahleova H, Lloren Jl, Mashchak A, Hill M, Fraser GE. Meal frequency and timing are associated with changes in body mass index in Adventist health study 2. J Nutr. 2017;147(9):1722-8.

38. Beccuti G, Monagheddu C, Evangelista A, Ciccone G, Broglio F, Soldati L, et al. Timing of food intake: Sounding the alarm about metabolic impairments? A systematic review. Pharmacol Res. 2017;125(Pt B):132-41.

39. Scagliusi FB, Ferriolli E, Pfrimer K, Laureano C, Cunha CS, Gualano B, et al. Characteristics of women who frequently under report their energy intake: a doubly labelled water study. Eur J Clin Nutr. 2009;63(10):1192-9.

40. Meng X, Kerr DA, Zhu K, Devine A, Solah VA, Wright J, et al. Under-reporting of energy intake in elderly Australian women is associated with a higher body mass index. J Nutr Health Aging. 2013;17(2):112-8.

41. Crane TE, Latif YA, Wertheim BC, Kohler LN, Garcia DO, Rhee JJ, et al. Does season of reported dietary intake influence diet quality? Analysis from the women's health initiative. Am J Epidemiol. 2019. https://doi.org/10.1093/aje/ kwz087 Epub ahead of print.

42. Connor Gorber S, Tremblay M, Moher D, Gorber B. A comparison of direct vs. self-report measures for assessing height, weight and body mass index: a systematic review. Obes Rev. 2007;8(4):307-26.

\section{Publisher's Note}

Springer Nature remains neutral with regard to jurisdictional claims in published maps and institutional affiliations. 